\title{
Prevalence of Adverse Drug Reactions to Second Line Anti Tuberculosis Drugs in Nigeria: A Cross-Sectional Study
}

\author{
Abideen Adedayo Ganiyu1,2, Yohanna Kambai Avong,3,4, Akinwumi Akinyede1, \\ Olusoji Mayowa Ige ${ }^{5}$, Osman El tayeb ${ }^{6}$, Fatai Taleatu ${ }^{2}$, Ayobami Omayeka ${ }^{2}$, \\ Victor Babawale7, Ibrahim Oreagba ${ }^{1}$
}

\author{
${ }^{1}$ Department of Pharmacology, Therapeutics and Toxicology, College of Medicine, University of Lagos, Lagos, Nigeria \\ ${ }^{2}$ Government Chest Hospital, Ibadan, Nigeria \\ ${ }^{3}$ Institute of Human Virology of Nigeria (IHVN), Abuja, Nigeria \\ ${ }^{4}$ University of Technology Sydney, Ultimo, Australia \\ ${ }^{5}$ University College Hospital, Ibadan, Nigeria \\ ${ }^{6}$ Damien Foundation Belgium, Nigeria Office, Ibadan, Nigeria \\ ${ }^{7}$ National Tuberculosis and Leprosy Control Programme (NTBLCP), Abuja, Nigeria \\ Email: zaag123@gmail.com
}

How to cite this paper: Ganiyu, A.A., Avong, Y.K., Akinyede, A., Ige, O.M., Osman, E., Taleatu, F., Omayeka, A., Babawale, V. and Oreagba, I. (2021) Prevalence of Adverse Drug Reactions to Second Line Anti Tuberculosis Drugs in Nigeria: A Cross-Sectional Study. Journal of Tuberculosis Research, 9, 90-102.

https://doi.org/10.4236/jtr.2021.92008

Received: April 21, 2021

Accepted: June 21, 2021

Published: June 24, 2021

Copyright () 2021 by author(s) and Scientific Research Publishing Inc. This work is licensed under the Creative Commons Attribution International License (CC BY 4.0).

http://creativecommons.org/licenses/by/4.0/

(c) (i) Open Access

\begin{abstract}
Introduction: Multidrug resistant tuberculosis (MDR-TB) is treated with second line antituberculosis drugs. These drugs are notorious for inflicting serious adverse drug reactions (ADRs), which many studies have shown causes a wide range of economic and health problems including death. Aim: The study examined the prevalence of ADRs, associated risk factors, sociodemographic association and outcomes among patients treated for MDR-TB at a comprehensive tuberculosis treatment center in Nigeria. Method: The study was conducted at the Government Chest Hospital, Jericho, Ibadan. We applied a retrospective assessment of patient treatment data and ADRs reports stored at the study site from March 2013 and February 2016. Subsequently, a prospective study of ADRs was conducted on patients admitted into the same hospital. Causality relationship between the drugs and the reported ADRs was determined with a specially validated tool. The outcomes assessed include recovery from the ADRs, death and permanent deafness from the ADRs. Extracted data were analyzed using SPSS version 22.0. Risk Ratio was calculated for the influence of risk factors for adverse drug reactions. Logistic regression was performed to test for the strength of relationships between risk factors and incidence of ADRs among patients. Result: Almost all the participants in this study reported adverse drug reaction [99\% (118/119)]. However, ototoxicity was the most prevalent ADR (35.3\%), followed by electrolyte imbalance (12.6\%), gastrointestinal track (10.1\%) and
\end{abstract}


psychiatric disorders (10.1\%). Being older than 35 years and HIV negative or having a healthy BMI were not significant risk factors for developing ADRs. Duration of ADR above one month was significantly associated with the outcome of ADR. Conclusion: Ototoxicity, electrolyte imbalance, psychiatric disorders and gastrointestinal tract problems were the most frequently reported ADRs. Healthcare providers, government and donor agencies supporting the treatment should ensure that hearing aids and other forms of support are readily made available for the affected patients.

\section{Keywords}

Multidrug Resistant Tuberculosis, ADR, Risk Factors, Prevalence

\section{Introduction}

Tuberculosis (TB) is a communicable disease that has emerged among the top 10 causes of death worldwide. It is the leading cause of death from a single infectious agent, ranking above HIV/AIDS [1]. TB is one of the major health problems in Nigeria and the country ranks $6^{\text {th }}$ out of 30 high burden countries for Tuberculosis globally and $1^{\text {st }}$ in Africa in one of the recent global reports by WHO [1].

Multidrug resistant tuberculosis (MDR-TB), which is more fatal than the normal TB, develops when the Mycobacterium tuberculosis develops resistant to the backbone treatment, which is rifampicin (R) and isoniazid (INH). The Nigerian Guidelines for treating MDRTB (2012) recommended the conventional regimen in which is administered over a 20-month period, 8 months intensive and 12 months continuation phase. The 8 months intensive phase had the injectable aminoglycoside kanamycin or capreomycin as the backbone. The conventional programmatic regimen with which MDR treatment started in Nigeria was composed as follows:

1) Oral fluoroquinolone-Levofloxacin;

2) Second line injectable-Kanamycin/Capreomycin;

3) Other core second line agents-Cycloserine;

4) Other core second line agents-Prothionamide;

5) Add-on agents-Pyrazinamide.

The conventional regimen was used in the Country from 2010 and until 2017 when it gave way to the shorter regimen after its adoption by the WHO in 2016. The injectable-based shorter regimen is given over a period of $9-11$ months with a combination of 7 drugs (High dose isoniazid, Ethambutol, Pyrazinamide, Prothionamide, Clofazimine, Moxifloxacin and an injectable aminoglycoside or cyclic peptide capreomycin). A transition to all oral bedaquiline-based regimen was yet to commence at the time of this study.

Government Chest hospital is a tuberculosis specialist and referral center for all forms of tuberculosis from drug susceptible tuberculosis (DSTB) to multidrug resistant tuberculosis (MDR-TB) and extensively drug resistant tuberculosis (XDR-TB) - all of which are referred to as drug resistant tuberculosis (DR-TB). 
MDR-TB patients are treated with more toxic, and more expensive second-line anti-TB drugs (SLDs) [2]. Due to the long duration of therapy and concurrent use of multiple second-line drugs, adverse drug reactions (ADRs) are regarded as one of the most important clinical considerations in patients undergoing MDR-TB treatment [3] [4] [5] [6] [7]. The ADRs range from mild adverse drug events (ADEs) such as nausea/vomiting, headache to life-threatening events (such as renal failure, hepatotoxicity) and death [8] [9] [10] [11] [12]. The treatment-related problems that ADRs can cause include temporary interruption or permanent discontinuation of chemotherapy [13], which in turn, diminishes the effectiveness of chemotherapy owing to no adherence. ADRs also escalate poor treatment outcomes, especially increasing the risk of developing extensively drug-resistant TB [4] [14].

Risk factors are defined as conditions or measurements associated with the probability of disease or death not necessarily recognized by the patient [15] [16] [17]. Managing risk factors for ADRs is crucial for improving patient safety, particularly for the elderly, comorbid, and polypharmacy patients [18]. ADRs have risk factors, and some are preventable. Risk factors can be categorized into five main categories, including patient, disease, medication, health service, and genetics [18]. In a recent study, the risk factors for presence of ADRs in MDR-TB patients were summarized to comprise: Old age, Malnutrition, Pregnancy and lactation, Alcohol addiction.

Liver failure, Chronic renal failure, HIV infection, Disseminated TB, Allergy/atopy, Anaemia, Diabetes Mellitus, Family history of ADRs, Patients receiving intermittent treatment, Patients receiving treatment for other comorbidities, in addition to anti-TB drug [19].

Few studies have described the occurrence and patterns of ADRs in Nigerian tuberculosis patients while specific studies in MDR patients are still fewer, yet, the impact of ADRs among drug resistant tuberculosis patients is well reported. None of these studies have examined the potential risk factors that predispose or aggravate the possible occurrence of ADRs among these groups of patients.

The study therefore aims to comprehensively analyze the prevalence of ADRs among patients treated at a comprehensive tuberculosis center in Nigeria over a period of five years.

\section{The Objectives Were}

1) To describe the characteristics of the patients.

2) To demonstrate the type and frequency of ADR of MDR-TB patients on admission.

3) To describe the risk factors associated with the incidence of ADR.

4) To describe the outcome of ADRs among the studied population.

\section{Method}

\subsection{Setting}

This study was conducted at the Government chest hospital Jericho Ibadan be- 
tween March 2013 and September 2018. The hospital is a referral center for chest-related diseases especially tuberculosis. This center treats all the different forms of TB from the drug susceptible TB to multidrug resistant and extensively drug resistant tuberculosis.

It serves the entire Country as the only referral center for the treatment of extensively drug resistant tuberculosis (XDR-TB) in addition to management of drug susceptible tuberculosis (DS-TB) and multidrug resistant tuberculosis (MDR-TB). Attempt was made to examine the patient characteristics, pattern of ADRs, outcome of the ADRs and associated risk factors.

\subsection{Study Population}

The study population is all MDR-TB patients who were admitted for treatment to the Government chest hospital Jericho Ibadan between March 2013 and September 2018.

\subsection{Sampling}

Total sample was used. All the patients treated within the period were included in the analysis.

\subsection{Study Design}

This study started as observational retrospective cohort study where documents, reports and treatment records of patients that were managed for multidrug resistant tuberculosis between March 2013 and February 2016 were scrutinized for records of adverse drug reactions experienced during treatment and captured into an excel template. This was in addition to those adverse drug reactions that have been formally reported to the National regulatory Agency responsible for the monitoring of adverse drug reaction as well as regulation of drugs, cosmetics and medical; devices (NAFDAC).Thereafter patients that were managed between March 2016 and September 2018 were actively monitored for incidence of adverse drug reactions. Adverse drug reactions were captured through direct observation by the team of healthcare providers of the patients, personal complaints rendered by the patients as well as analysis of investigational reports used for follow up of the patients' treatment especially audiometry and blood chemistry reports. Therefore the study adopted a partly retrospective and partly prospective method. Causality relationship between the drugs and the reported adverse drug reactions was determined with a special tool developed by the collaborative efforts of NAFDAC and Institute of human Virology of Nigeria (IHVN) in support of Structured Pharmacovigilance training initiatives (SPHARTI) in Nigeria. This was in addition to the application of the Naronjo causality assessment algorithm.

Extracted data was analyzed using SPSS version 22.0. Univariate analysis using descriptive statistics was used to summarize the results. Chi square test was done to determine association between dependent and independent variables. Risk 
Ratio was calculated for the influence of risk factors for adverse drug reactions. Logistic regression was performed to test for the strength of relationships between risk factors and incidence of ADR among patients. Statistical significance was set at $\mathrm{p}<0.05$.

The study outcome was categorized into three broad categories: Recovered, died and permanent disability (deafness).

\section{Results}

Table 1 presents the characteristics of the participants in this study. Of the 119 participants that were included in the study, 118 reported ADR, equivalent to $99 \%$. Men (66.4\%), mean age (37.6 \pm 12.1 years), normal weights $(51.3 \%)$ and nearly $35 \%$ of the participants were younger adults, with an age range of 25 to 34 years.

\section{Prevalence of ADR}

Table 2(a) presents the prevalence of various groups of adverse drug reactions among the study populations.

Table 2(a) also shows the prevalence of ADR among all the 119 MDR-TB patients who participated in this study, 9.2\% had complaints related to allergy, $10.9 \%$ arthralgia, $2.5 \%$ had cardiovascular related adverse events, $12.6 \%$ reported issued relating to electrolyte imbalance. About $10.1 \%$ had GIT related adverse events, $1.7 \%$ reported gynaecomastia, $4.2 \%$ had haematological reactions, $1.7 \%$ had neurological reactions, $35.3 \%$ reported ototoxicity, $10.1 \%$ had psychiatric disorders, $1.7 \%$ reported superinfection.

Table 1. Bio data among MDR-TB patients.

\begin{tabular}{ccc}
\hline Sex: & $\begin{array}{c}\text { Frequency } \\
\text { (n) }\end{array}$ & $\begin{array}{c}\text { Percent } \\
(\%)\end{array}$ \\
Male & 79 & 66.4 \\
Female & 40 & 33.6 \\
\hline Age: $37.6 \pm 12.1$ years & & \\
$15-24$ years & 13 & 10.9 \\
$25-34$ years & 41 & 34.5 \\
$35-44$ years & 35 & 29.4 \\
$45-54$ years & 16 & 13.4 \\
$55-64$ years & 10 & 8.4 \\
$>65$ years & 4 & 3.4 \\
BMI scale: & & 44.5 \\
Underweight $(<18.5)$ & 53 & 51.3 \\
Normal $(18.5-24.9)$ & 61 & 3.4 \\
Overweight $(25.0-29.9)$ & 4 & 0.8 \\
Obesity (30.0 - 39.9) & 1 & 0.0 \\
Morbid obesity $(40.0+)$ & 0 & 100.0 \\
\hline & 119 &
\end{tabular}


Table 2. (a) Prevalence of Adverse Drug Reactions (ADR) among MDR-TB patients; (b) Pattern of ADRs among MDR-TB patients across Socio-demographic grouping.

(a)

\begin{tabular}{ccc}
\hline Adverse Drug Reactions & $\begin{array}{c}\text { Frequency } \\
\text { (n) }\end{array}$ & $\begin{array}{c}\text { Percent } \\
(\%)\end{array}$ \\
\hline Allergy & 11 & 9.2 \\
Arthralgia & 13 & 10.9 \\
Cardiovascular & 3 & 2.5 \\
Electrolyte imbalance & 15 & 12.6 \\
Gastrointestinal tract & 12 & 10.1 \\
Gynaecomastia & 2 & 1.7 \\
Haematological & 5 & 4.2 \\
Neurological & 2 & 1.7 \\
Ototoxicity & 42 & 35.3 \\
Psychiatric disorders & 12 & 10.1 \\
Superinfection & 2 & 1.7 \\
\hline
\end{tabular}

(b)

\begin{tabular}{ccccc}
\hline Adverse Drug Reactions & $\begin{array}{c}\text { Age }>\text { 35 years } \\
(\mathbf{n}=\mathbf{5 8}) \\
\mathbf{n}(\%)\end{array}$ & p-value & $\begin{array}{c}\text { Female gender } \\
(\mathbf{n}=40) \\
\mathbf{n}(\%)\end{array}$ & p-value \\
\hline Allergy & $5(8.6)$ & 0.536 & $4(10.0)$ & 0.540 \\
Arthralgia & $5(8.6)$ & 0.560 & $3(7.5)$ & 0.539 \\
Cardiovascular & $0(0.0)$ & 0.244 & $0(0.0)$ & 0.550 \\
Electrolyte imbalance & $9(15.5)$ & 0.414 & $8(20.0)$ & 0.141 \\
Gastrointestinal tract & $8(13.8)$ & 0.232 & $1(2.5)$ & 0.043 \\
Gynaecomastia & $2(3.4)$ & 0.235 & $1(2.5)$ & 0.561 \\
Haematological & $2(3.4)$ & 0.524 & $2(5.0)$ & 0.548 \\
Neurological & $1(1.7)$ & 0.739 & $0(0.0)$ & 0.550 \\
Ototoxicity & $21(36.2)$ & 0.850 & $14(35.0)$ & 0.564 \\
Psychiatric disorders & $4(6.9)$ & 0.364 & $5(12.5)$ & 0.534 \\
Superinfection & $1(1.7)$ & 0.739 & $2(5.0)$ & 0.111 \\
\hline
\end{tabular}

Ototoxicity had the highest prevalence, 40 (35.2\%), followed by electrolyte imbalance, $15(12.6 \%)$ and arthralgia (13 (10.9\%). Gastrointestinal tract complications, $12(10.1 \%)$ and Psychiatric disorders, $12(10.1 \%)$ followed at the same level of prevalence.

Table 2(b) presents the association of different categories of ADR with female gender and advanced age on their reported ADRs at $5 \%$ level of significance.

The female gender and being more than 35 years did not expose the participants to a higher risk of ADRs. 
Being $>35$ years and female, had no significant association with occurrence of adverse events, except in the case GIT related adverse event which showed significant association with the female gender.

The table above shows the significant relationship that might exist between age of patients above 35 years $(n=58$; as against those who are younger) and ADRs, reporting critical level to be at $5 \%$ level of significance. In the same way, the table is also reporting significant relationship that might exist between female patients ( $\mathrm{n}=40$; as against male patients) and ADRs, also at $5 \%$ level of significance. Results showed that female gender as a pattern of ADR among MDR-TB patients is significantly associated with having ADR related to the gastrointestinal tract.

Table 3 presents the risk factors and their association with the outcome at 5\% level of significance. There are three outcomes. These are "recovered", "died" and "permanently deaf". There was no significant association between the age of patients above 35 years old (age risk) and the study outcomes $(p=0.420)$. Similarly, no significant association was observed between the female gender and the study outcomes $(p=0.750)$. Furthermore, there was no significant association between healthy BMI and the study outcomes $(\mathrm{p}=0.815)$. Moreover, there was no significant association between being infected with HIV and the study outcomes $(\mathrm{p}=0.450)$. In summary, Being older than 35 years $(\mathrm{p}=0.420)$, woman ( $\mathrm{p}$ $=0.750)$, and having a healthy BMI $(\mathrm{p}=0.815)$ or being HIV negative $(\mathrm{p}=$ 0.450 ), had no significant association with recovery, death and permanently deaf.

Table 4 presents the onset and duration of adverse drug reactions among MDR-TB patients and the significant relationship that might exist between the onset and duration of days and the study outcomes at 5\% level of significance.

Table 3. Risk factors for ADRs among MDR-TB patients (Socio-demographic factors and Outcome of ADR).

\begin{tabular}{|c|c|c|c|c|c|c|}
\hline & \multirow[b]{2}{*}{$\begin{array}{l}\text { Frequency } \\
\text { (n) }\end{array}$} & \multirow[b]{2}{*}{$\begin{array}{l}\text { Percent } \\
\text { (\%) }\end{array}$} & \multicolumn{3}{|c|}{ Study Outcome } & \multirow[b]{2}{*}{ p-value } \\
\hline & & & $\begin{array}{l}\text { Recovered } \\
\text { n (\%) }\end{array}$ & $\begin{array}{l}\text { Died } \\
\mathrm{n}(\%)\end{array}$ & $\begin{array}{c}\text { Permanently } \\
\text { Deaf } \\
\text { n (\%) }\end{array}$ & \\
\hline \multicolumn{7}{|c|}{ Advance age (>35): } \\
\hline Yes & 58 & 48.7 & $46(46.9)$ & $4(44.4)$ & $8(66.7)$ & \multirow{2}{*}{0.420} \\
\hline No & 61 & 51.3 & $52(53.1)$ & $5(55.6)$ & $4(33.3)$ & \\
\hline \multicolumn{7}{|c|}{ Gender risk (Female): } \\
\hline Yes & 40 & 33.6 & $34(34.7)$ & $2(22.2)$ & $4(33.3)$ & \multirow{2}{*}{0.750} \\
\hline No & 79 & 66.4 & $64(65.3)$ & $7(77.8)$ & $8(66.7)$ & \\
\hline \multicolumn{7}{|c|}{ Healthy BMI: } \\
\hline Yes & 61 & 51.3 & $50(51.0)$ & $4(44.4)$ & $7(58.3)$ & \multirow{2}{*}{0.815} \\
\hline No & 58 & 48.7 & $48(49.0)$ & $5(55.6)$ & $5(41.7)$ & \\
\hline \multicolumn{7}{|l|}{ HIV: } \\
\hline Negative & 114 & 95.8 & $94(95.9)$ & $8(88.9)$ & $12(100.0)$ & \multirow{3}{*}{0.450} \\
\hline \multirow[t]{2}{*}{ Positive } & 5 & 4.2 & $4(4.1)$ & $1(11.1)$ & $0(0.0)$ & \\
\hline & 119 & 100.0 & $\begin{array}{c}98 \\
(100.0)\end{array}$ & $\begin{array}{c}9 \\
(100.0)\end{array}$ & $\begin{array}{c}12 \\
(100.0)\end{array}$ & \\
\hline
\end{tabular}


Table 4. Onset and duration days of ADRs among MDR-TB patients.

\begin{tabular}{|c|c|c|c|c|c|c|}
\hline & \multirow[b]{2}{*}{$\begin{array}{l}\text { Frequency } \\
\text { (n) }\end{array}$} & \multirow[b]{2}{*}{$\begin{array}{c}\text { Percent } \\
(\%)\end{array}$} & \multicolumn{3}{|c|}{ Study Outcome } & \multirow[b]{2}{*}{$\mathrm{p}$-value } \\
\hline & & & $\begin{array}{c}\text { Recovered } \\
\text { n (\%) }\end{array}$ & $\begin{array}{l}\text { Died } \\
\mathrm{n}(\%)\end{array}$ & $\begin{array}{c}\text { Permanently } \\
\text { Deaf } \\
\text { n (\%) }\end{array}$ & \\
\hline \multicolumn{7}{|l|}{ Onset days: } \\
\hline$\leq$ One week & 10 & 8.4 & $10(10.2)$ & $0(0.0)$ & $0(0.0)$ & \multirow{5}{*}{0.636} \\
\hline Two weeks & 9 & 7.6 & $8(8.2)$ & $1(11.1)$ & $0(0.0)$ & \\
\hline Three weeks & 4 & 3.4 & $4(4.1)$ & $0(0.0)$ & $0(0.0)$ & \\
\hline One month & 17 & 14.3 & $14(14.3)$ & $2(22.2)$ & $1(8.3)$ & \\
\hline$>$ One month & 79 & 66.4 & $62(63.3)$ & $6(66.7)$ & $11(91.7)$ & \\
\hline \multicolumn{7}{|l|}{ Duration days: } \\
\hline$\leq$ One week & 11 & 9.2 & $10(10.2)$ & $1(11.1)$ & $0(0.0)$ & \multirow{7}{*}{$<0.0001$} \\
\hline Two weeks & 12 & 10.1 & $9(9.2)$ & $3(33.3)$ & $0(0.0)$ & \\
\hline Three weeks & 16 & 13.4 & $15(15.3)$ & $1(11.1)$ & $0(0.0)$ & \\
\hline One month & 22 & 18.5 & $21(21.4)$ & $0(0.0)$ & $1(8.3)$ & \\
\hline$>$ One month & 49 & 41.2 & $43(43.9)$ & $4(44.5)$ & $2(16.7)$ & \\
\hline \multirow[t]{2}{*}{ No report } & 9 & 7.6 & $0(0.0)$ & $0(0.0)$ & $9(75.0)$ & \\
\hline & 119 & 100.0 & $\begin{array}{c}98 \\
(100.0)\end{array}$ & $\begin{array}{c}9 \\
(100.0)\end{array}$ & $\begin{array}{c}12 \\
(100.0)\end{array}$ & \\
\hline
\end{tabular}

There was no significant relationship between the onset and the study outcomes $(p=0.636)$. Nevertheless, the duration patients lived with the ADRs was significantly associated with all the study outcomes $(\mathrm{p}<0.0001)$.

\section{Discussion}

This study investigated the prevalence, risk factors and the consequence of adverse drug reactions among drug resistant tuberculosis patients treated with second line anti TB drugs in a comprehensive tuberculosis treatment center in Nigeria.

The major findings of this study are: 1) Almost all the participants reported a wide range of ADRs beyond what has been reported in previous studies both in Nigeria and outside Nigeria 2) A detection of at least four ADRs that were frequently reported in the literature 3) An observation that HIV status and older age were not significant risk factors for the development of ADRs and 4) the onset of ADR has no association with outcomes studied, but the duration of the ADR does. The strength of this study includes compliance to the STROBE guidelines and data coverage of a period of five years from a dedicated infectious hospital for the treatment of drug resistant tuberculosis in Nigeria. The study is limited by the non-availability of patients without adverse drug reaction for better comparison. The sample size which in any case was total sample of all patients enrolled and treated for over the 5-year period was not large enough for robust analysis. 


\subsection{Proportion of Adverse Drug Reactions Reported}

The prevalence of ADR was about $99 \%$, higher than the $44 \%$ previously reported in a nationwide cohort of patients treated for MDR-TB [20]. The difference in findings between the cohort study and this study could be the improvement in reporting capacity of healthcare workers that followed the SPHARTI project [21], in which healthcare workers (medical doctors, pharmacists and nurses) were trained on prompt and accurate reporting of ADRs. It is also higher than previously reported in other studies in multidrug resistant tuberculosis management outside Nigeria, such as $46.9 \%$ reported by Rajendra et al. [22] and $57.3 \%$ in a meta-analysis by Shansan et al. [23]. Furthermore, it is higher than the peak of the range reported in other studies, such as $69 \%$ to $96 \%$ [24]-[40]. The reasons for the difference in the prevalence of adverse events reporting across studies have been reported by Rajendra et al. [22]. Typically, variation in demographic profiles of cohorts of patients, differences in definitions of adverse events' terminologies, as adopted by physicians, whether the adverse event was reported by patient (subjective) or detected by clinician (objective), the basis of clinical evidence along with feasibility of monitoring with serial laboratory investigations are some of the factors [22]. However, in a more recent retrospective cohort study of 152 patients, 650 ADRs were documented, of which $56.3 \%$ were serious ADRs. Around $98 \%$ of patients developed at least one ADR and $92.6 \%$ of the patients experienced at least one serious ADR [40]. These findings draw very close to the findings of this study probably due to its exhaustive and thorough data gathering.

\subsection{The Most Frequently Reported Adverse Drug Reactions}

Ototoxicity was the most prominent adverse reactions reported by the patients, with $35.3 \%$ higher than the pooled estimate of $14.6 \%$ in a Meta-analysis [23] and also higher than the nationwide cohort study [2]. The utilization of follow up audiometric reports and patients' treatments folders at our study site afforded better detection and capturing of the adverse events than relying on aggregated reports from many sites with different commitment, training and capacity to detect and report adverse events. All the same, the reported prevalence still falls within the ranges documented in the literature of $12 \%$ - 70\%. [3] [4] [24] [25] [31] [34]. Rajendra et al. [22] reported that $23.6 \%$ is under-reporting because routine audiometry was not performed on the patient during the intensive phase of the treatment and many incidence and episodes of ototoxicity would have gone unreported. We were painstaking not to miss any of the episodes in the course of treatment of the patients. In this study, proactive measures were taken to address the complaint or observed ototoxicity; this could be responsible for a lower incidence than the highest reported.

Electrolytes imbalance, which is mostly presented as hypokalemia, ranked second in the prevalence of the adverse events among the patients (12.6\%) and closely followed by gastrointestinal adverse events (10.1\%). The electrolyte im- 
balance is associated with the injectable amino glycoside in the MDR-TB regimen. The hypokalemia reported in this study was less than the $23 \%$ reported by Rajebdra et al. [22] probably due to concurrent mitigation and management with dietary supplements and oral potassium supplement. It was however higher than the reported in the nationwide cohort study possibly due to increased capacity and efficiency developed in the reporting of ADRs coupled with active utilization of monthly blood chemistry report to detect early enough any incidence of electrolyte imbalance. Psychiatric disorders and gastrointestinal tract complications were also reported in this study, consistent with what was reported in the Nigeria's cohort study [2].

\subsection{Risk Factors}

Unlike in some previous studies where body weight (BMI) low was associated with increased risk of ADR [19], no association was found in this study and the reason might have been the adjustment of dosages according to the weight bands that was the standard practice as stipulated by the national TB treatment guideline in Nigeria. In this study, association was found between low body weight and risk of ADR same dosed were being given and this exposed the patients to greater toxicity of the drugs which were most likely dose dependent [19]. HIV negative status and gender were not associated with increased risk and this was in tandem with findings in some previous studies.

\subsection{Onset and Duration of Adverse Drug Reactions}

There was no significant relationship between onset of ADRs and the study outcome (recovered, died and permanently deafness).However, a significant association between the duration of ADRs and the study outcome was observed. A larger proportion of the adverse events (41.2\%) were prolonged for extended period, with the risk of causing death as reported in some studies [2].

The potential weakness of this study is the reliance on retrospective data and the small sample size. However, ADRs report are reliable sources of information for post marketing drug safety, and we hope that the findings of this study will contribute to the well documented fact that antituberculosis medications are toxic and patients using such drugs require intensive clinical monitoring. It is also important these ADRs are consistently reported to the medicines regulatory agencies to promote drug regulation.

\section{Conclusion}

Patients receiving treatment for drug resistant tuberculosis with second line antituberculosis regimen are disproportionately exposed to the risk of ADRs, which may include debilitating conditions like ototoxicity and psychiatric disorders or fatal events, such as electrolyte imbalance. The overwhelming need for safer antituberculosis medications and the intensive monitoring of patients that must accompany the use of these drugs is again brought to global focus by these 
findings. Developing strategies to reduce the incidence of ADRs will be of immense benefit for the optimization of the regimens which have proven to be highly effective in the management of MDR-TB.

\section{Conflicts of Interest}

The authors declare no conflicts of interest regarding the publication of this paper.

\section{References}

[1] Global TB Report 2019. https://reliefweb.int/report/world/global-tuberculosis-report-2019

[2] Basit, A., Ahmad, N., Khan, A.H., et al. (2014) Predictors of Two Months Culture Conversion in Multidrug-Resistant Tuberculosis: Findings from a Retrospective Cohort Study. PLOS ONE, 9, e93206. https://doi.org/10.1371/journal.pone.0093206

[3] Baghaei, P., Tabarsi, P., Dorriz, D., et al. (2011) Adverse Effects of Multidrug-Resistant Tuberculosis Treatment with a Standardized Regimen: A Report from Iran. American Journal of Therapeutics, 18, e29-e34. https://doi.org/10.1097/MJT.0b013e3181c0806d

[4] Bloss, E., Kuksa, L., Holtz, T.H., et al. (2010) Adverse Events Related to Multidrug-Resistant Tuberculosis Treatment, Latvia, 2000-2004. The International Journal of Tuberculosis and Lung Disease, 14, 275-281.

[5] Carroll, M.W., Lee, M., Cai, Y., et al. (2012) Frequency of Adverse Reactions to First- and Second-Line Anti-Tuberculosis Chemotherapy in a Korean Cohort. The International Journal of Tuberculosis and Lung Disease, 16, 961-966. https://doi.org/10.5588/ijtld.11.0574

[6] Torun, T., Gungor, G., Ozmen, I., et al. (2005) Side Effects Associated with the Treatment of Multidrug-Resistant Tuberculosis. The International Journal of $\mathrm{Tu}$ berculosis and Lung Disease, 9, 1373-1377.

[7] Furin, J.J., Mitnick, C.D., Shin, S.S., et al. (2001) Occurrence of Serious Adverse Effects in Patients Receiving Community-Based Therapy for Multidrug-Resistant Tuberculosis. The International Journal of Tuberculosis and Lung Disease, 5, 648-655.

[8] Rozich, J.D., Haraden, C.R. and Resar, R.K. (2003) Adverse Drug Event Trigger Tool: A Practical Methodology for Measuring Medication Related Harm. BMJ Quality \& Safety, 12, 194-200. https://doi.org/10.1136/qhc.12.3.194

[9] Runciman, W.B., Roughead, E.E., Semple, S.J. and Adams, R.J. (2003) Adverse Drug Events and Medication Errorsin Australia. International Journal for Quality in Health Care, 15, i49-i59. https://doi.org/10.1093/intqhc/mzg085

[10] Pirmohamed, M., James, S., Meakin, S., Green, C., Scott, A.K., Walley, T.J., Farrar, K., Park, B.K. and Breckenridge, A.M. (2004) Adverse Drug Reactions as Cause of Admission to Hospital: Prospective Analysis of 18,820 Patients. BMJ, 329, 15-19. https://doi.org/10.1136/bmj.329.7456.15

[11] Bates, D.W., Cullen, D.J., Laird, N., Petersen, L.A., Small, S.D., Servi, D., Laffel, G., Sweitzer, B.J., Shea, B.F., Hallisey, R., et al. (1995) Incidence of Adverse Drug Events and Potential Adverse Drug Events. Implications for Prevention. ADE Prevention Study Group. JAMA, 274, 29-34. https://doi.org/10.1001/jama.274.1.29

[12] Kohn, L.T., Corrigan, J.M. and Donaldson, M.S. (2000) To Err is Human: Building a Safer Health System. https://pubmed.ncbi.nlm.nih.gov/25077248/ 
[13] American Thoracic Society, Centers for Disease Control and Prevention (CDC), Infectious Diseases Society (2003) Treatment of Tuberculosis. American Journal of Respiratory and Critical Care Medicine, 167, 603-662. https://doi.org/10.1164/rccm.167.4.603

[14] Leimane, V., Riekstina, V., Holtz, T.H., et al. (2005) Clinical Outcome of Individualised Treatment of Multidrug-Resistant Tuberculosis in Latvia: A Retrospective Cohort Study. The Lancet, 365, 318-326. https://doi.org/10.1016/S0140-6736(05)17786-1

[15] Willadsen, T.G., Bebe, A., Køster-Rasmussen, R., Jarbøl, D.E., Guassora, A.D., Waldorff, F.B., Reventlow, S. and Olivarius, N.F. (2016) The Role of Diseases, Risk Factors and Symptoms in the Definition of Multimorbidity-A Systematic Review. Scandinavian Journal of Primary Health Care, 34, 112-121.

https://doi.org/10.3109/02813432.2016.1153242

[16] Nexøe, J., Halvorsen, P.A. and Kristiansen, I.S. (2007) Review Article: Critiques of the Risk Concept-Valid or Not? Scandinavian Journal of Public Health, 35, 648-654. https://doi.org/10.1080/14034940701418897

[17] Reventlow, S., Hvas, A.C. and Tulinius, C. (2001) “In Really Great Danger?” The Concept of Risk in General Practice. Scandinavian Journal of Primary Health Care, 19, 71-75. https://doi.org/10.1080/028134301750235268

[18] Zhou, L. and Rupa, A.P. (2017) Categorization and Association Analysis of Risk Factors for Adverse Drug Events. European Journal of Clinical Pharmacology, 74, 389-404. https://doi.org/10.1007/s00228-017-2373-5

[19] Caminero, J.A., Lasserra, P., Piubello, A. and Singla, R. (2018) Adverse Antituberculosis Drug Events and Their Management. In: Migliori, G.B., Bothamley, G., Duarte, R. and Rendon, A., Eds., Tuberculosis [Internet], European Respiratory Society, Sheffield, 205-227. http://erspublications.com/lookup/doi/10.1183/2312508X.10021617

[20] Avong, Y.K., Isaakidis, P., Hinderaker, S.G., et al. (2015) Doing No Harm? ADRs in a Nation-Wide Cohort of Patients with Multidrug-Resistant Tuberculosis in Nigeria. PLoS ONE, 10, e0120161. https://doi.org/10.1371/journal.pone.0120161

[21] Avong, Y.K., Jatau, B., Gurumnaan, R., Danat, N., Okuma, J., Usman, I., et al. (2018) Addressing the Under-Reporting of Adverse Drug Reactions in Public Health Programs Controlling HIV/AIDS, Tuberculosis and Malaria: A Prospective Cohort Study. PLoS ONE, 13, e0200810. https://doi.org/10.1371/journal.pone.0200810

[22] Prasad, R., Singh, A., Srivastava, R., Hosmane, G.B., Kushwaha, R.A.S. and Jain, A. (2016) Frequency of Adverse Events Observed with Second-Line Drugs among Patients Treated for Multidrug-Resistant Tuberculosis. Indian Journal of Tuberculosis, 63, 106-114. https://doi.org/10.1016/j.ijtb.2016.01.031

[23] Wu, S., Zhang, Y., Sun, F., Chen, M., Zhou, L., Wang, N. and Zhan, S. (2013) Adverse Events Associated With the Treatment of Multidrug-Resistant Tuberculosis: A Systematic Review and Meta-Analysis. American Journal of Therapeutics, 23, e521e530. https://doi.org/10.1097/01.mjt.0000433951.09030.5a

[24] Tahaoglu, K., Torun, T., Sevim, T., et al. (2001) The Treatment of MDRTB in Turkey. The New England Journal of Medicine, 345, 170-174. https://doi.org/10.1056/NEJM200107193450303

[25] Papastavros, T., Dolovich, L.R., Holbrook, A., Whitehead, L. and Loeb, M. (2002) Adverse Events Associated with Pyrazinamide and Levofloxacin in the Treatment of MDR-TB. CMAJ, 167, 131-136.

[26] Nathanson, E., Gupta, R., Huamani, P., et al. (2005) Adverse Events in the Treat- 
ment of MDR-TB: Results from the DOTS-Plus Initiative. The International Journal of Tuberculosis and Lung Disease, 9, 1027-1033.

[27] Nahar, B.L., Mosharrof Hossain, A.K.M., Islam, M.M. and Saha, D.R. (2006) A Comparative Study on the Adverse Effects of Two Antituberculosis Drugs Regimen in Initial Two-Month Treatment Period. Bangladesh Journal of Pharmacology, 1, 51-57. https://doi.org/10.3329/bjp.v1i2.488

[28] Tupasi, T.E., Gupta, R., Quelapio, M.I.D., Orillaza, R.B., et al. (2006) Feasibility and Cost-Effectiveness of Treating MDR-TB: A Cohort Study in the Philippines. PLoS Medicine, 3, e352. https://doi.org/10.1371/journal.pmed.0030352

[29] Cox, H.S., Kalon, S., Allamuratova, S., et al. (2007) MDR-TB Treatment Outcomes in Karakalpakstan, Uzbekistan: Treatment Complexity and XDR-TB among Treatment Failures. PLoS ONE, 2, e1126. https://doi.org/10.1371/journal.pone.0001126

[30] Shin, S.S., Pasechnikov, A.D., Gelmanova, I.Y., et al. (2007) Adverse Reactions among Patients Being Treated for MDR-TB in Tomsk, Russia. The International Journal of Tuberculosis and Lung Disease, 11, 1314-1320.

[31] Lanternier, F., Dalban, C., Perez, L., Bricaire, F., Costagliola, D. and Caumes, E. (2007) Tolerability of Anti-Tuberculosis Treatment and HIV Sero-Status. The International Journal of Tuberculosis and Lung Disease, 11, 1203-1209.

[32] Seung, K.J., Omatayo, D.B., Keshavjee, S., Furin, J.J., Farmer, P.E. and Satti, H. (2009) Early Outcomes of MDR-TB Treatment in a High HIV Prevalence Setting in Southern Africa. PLoS ONE, 4, e7186. https://doi.org/10.1371/journal.pone.0007186

[33] Palmero, D., Cruz, V., Museli, T., Pavlovsky, H., Fernandez, J. and Waisman, J. (2010) Adverse Drug Reactions in MDR-TB. Medicina (B Aires), 70, 427-433.

[34] Sagwa, E., Mantel-Teeuwisse, A.K., Ruswa, N., et al. (2012) The Burden of Adverse Events during Treatment of Drug-Resistant Tuberculosis in Namibia. Southern Med Review, 5, 6-13.

[35] Van der Walt, M., Lancaster, J., Odendaal, R., Davis, J.G. and Shean, K. (2013) Serious Treatment Related Adverse Drug Reactions amongst Anti-Retroviral Naive MDR-TB Patients. PLoS ONE, 8, e58817.

https://doi.org/10.1371/journal.pone.0058817

[36] Singla, R., Sarin, R., Khalid, U.K., Mathuria, K. and Singla, N. (2009) Seven-Year DOTS-Plus Pilot Experience in India: Results, Constraints and Issues. The International Journal of Tuberculosis and Lung Disease, 13, 976-981.

[37] Joseph, P., Desai, V.B., Mohan, N.S., Fredrick, J.S. and Ramachandran, R. (2011) Outcome of Standardized Treatment for Patients with MDR-TB from Tamil Nadu, India. Indian Journal of Medical Research, 133, 529-534.

[38] Saakidis, P., Cox, H.S., Varghese, B., Montaldo, C. and Da Silva, E. (2011) Ambulatory MDR-TB Treatment Outcomes in a Cohort of HIV-Infected Patients in a Slum Setting in Mumbai, India. PLoS ONE, 6, e28066.

https://doi.org/10.1371/journal.pone.0028066

[39] Isaakidis, P., Varghese, B., Mansoor, H., Cox, H.S. and Ladomirska, J. (2012) Adverse Events among HIV/MDR-TB Co-Infected Patients Receiving Antiretroviral and Second Line Anti-TB Treatment in Mumbai, India. PLoS ONE, 7, e40781. https://doi.org/10.1371/journal.pone.0040781

[40] Russom, M., Verhamme, K., Karimi, L. and Ahmed, H. (2018) Nature, Magnitude and Risk Factors of Adverse Drug Reactions in Multidrug Resistant TB Patients in Eritrea. European Respiratory Journal, 52, PA4746. https://erj.ersjournals.com/content/52/suppl_62/PA4746 https://doi.org/10.1183/13993003.congress-2018.PA4746 